Keywords: Corrosion Monitoring

Waste Tank

Reactor

Technique

Survey

Retention:

Permanent

\title{
A SURVEY OF TECHNIQUES FOR CORROSION MONITORING (U)
}

\section{J. I. Mickalonis}

SAVANNAH RIVER TECHNOLOGY CENTER

Equipment \& Materials Technology Department

Materials Technology Section

ISSUED: October, 1992

\begin{tabular}{|c|}
\hline UNCLASSIFIED \\
DOES NOT CONTAN \\
UNCLASSIFIED CONTROLLED NUCLEAR INFORMATION \\
$D$. Thomen Ralui \\
Reviewing Officlal and Authorized Derivative Classifier \\
Date: $10 / 20 / 9 \alpha$ \\
\hline
\end{tabular}

Westinghouse Savannah River Company Sayonnah River Site Aiken, SC 29808

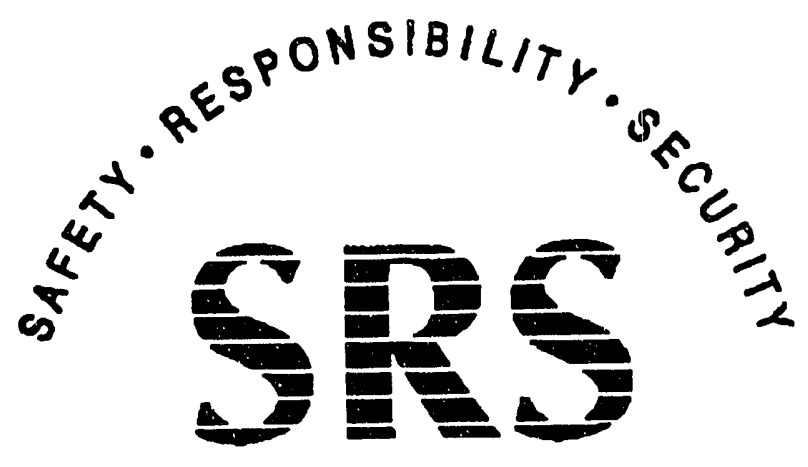

SAVANNAH RIVER SITE

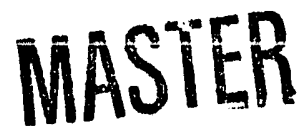


WSRC-TR-92-472 (U)

THIS PAGE INTENTIONALLY LEFT BLANK 
WSRC-TR-92-472 (U)

\section{CONTENTS}

PAGE

$\begin{array}{ll}\text { SUMMARY } & 1\end{array}$

INTRODUCTION 1

CURRENT SRS CORROSION MONITORING TECHNIQUES 2

Visual Inspection $\quad 2$

Nondestructive Examination 2

Solution Analysis 2

Process Monitoring 3

Coupon Immersion $\quad \mathbf{3}$

ELECTRICAL RESISTANCE TECHNIQUE 3

ELECTROCHEMICAL TECHNIQUES 4

Potential Measurements 4

Linear Polarization Resistance 5

Potentiodynamic Polarization 6

Zero Resistance Ammetry 6

Electrochemical Impedance Spectroscopy 6

Electrochemical Noise Measurement 7

CORROSION MONTTORNG EQUIPMENT 7

$\begin{array}{ll}\text { CONCLUSIONS } & 8\end{array}$

$\begin{array}{ll}\text { ACKNOWLEDGEMENTS } & 8\end{array}$

$\begin{array}{ll}\text { REFERENCES } & 9\end{array}$ 
G.el. Mickalonis

Date:

$10 / 14 / 92$

f. I. Mickalonis, AUTHOR

Materials Applications \& Corrosion Technology Group

MATERIALS TECHNOLOGY SECTION

Zusce tf Plevertio

B. J. Wiersina, TECHNICAL REVIEWER

Materials Applications \& Corrosion Technology Group

MATERIALS TECHNOLOGY SECTION

Cons Moun

Date: $10 / 19 / 92$

J. E. Marra, MANAGER

Materials Appllcations \& Corrosion technology Group

MATERIALS TECHNOLOGY SECTION

T. <. Ceneces.

Date:

$10 / 2 \cdot 192$

T. L. Capeletti, MANAGER

MATERIALS TECHNOLOGY SECTION 


\title{
A SURVEY OF TECHNIOUES FOR CORROSION MONITORING (U)
}

\author{
John I. Mickalonis \\ Westinghouse Savannah River Company \\ Savannah River Technology Center \\ Aiken, SC 29808
}

\section{SUMMARY}

Corrosion monitoring techniques have improved with advances in instrumentation technology and corrosion research. Older techniques, such as coupon immersion, generally provide historical information. The new electrochemical techniques, which have not been used widely at SRS, allow on-line monitoring and correlation with process changes. These techniques could improve the corrosion assessment of the waste tanks to be used for In-Tank Precipitation and Extended Sludge Processing. A task was initiated to place an electrochemical probe into tank 48 for testing the utility of this technique for waste tank applications.

\section{INTRODUCTION}

Corrosion monitoring at the Savannah River Site (SRS) has been a standard practice since the early fifties. A number of techniques which have been used in the reactor and waste tank farm areas include visual inspections; nondestructive examination such as ultrasonics and eddy current; solution analyses such as measurements of pH and inhibitor concentrations; process monitoring of parameters such as pressure and temperature; and coupon immersion. These techniques provided historical information about the extent of corrosion, which was used to assess the materials of construction and to verify the integrity of process equipment. Advanced monitoring techniques are now available which provide direct on-line information about corrosion. This type of monitoring is essential for understanding and measuring corrosion that is induced by process changes or upset conditions. Corrosion rate measurements, correlation of process and operational changes, and process control are possible. Many of the new techniques, besides the electrical resistance method, are based on the electrochemical theory of corrosion. The present SRS corrosion monitoring program will be enhanced by including newer techniques, especially for the high-level waste storage tanks.

This report is a review of corrosion monitoring techniques that are presently used at SRS and the more advanced methods including electrical resistance and electrochemical techniques. Several recent corrosion monitoring techniques, such as hydrogen probes, surface activation, and thermography, are not discussed because of their limited application and additional limits imposed by SRS processes. The electrochemical techniques include potential measurements, linear polarization resistance, potentiodynamic polarization, zero resistance ammetry, impedance spectroscopy, and electrochemical noise measurements. Each technique has advantages and disadvantages and provides certain types of corrosion data. Any single technique, therefore, is insufficient to completely characterize a corrosion condition. Suppliers of corrosion monitoring equipment are briefly discussed with an emphasis on the more advanced techniques. 
Techniques can be classified in various ways by the type of collected data. One data type is not necessarily better than another since different information is obtained which can be used as complimentary or supplementary. Two classifications will be used in this review: 1) direct and indirect and 2) instantaneous and historical. Direct data is a measurement of the corrosion rate, while indirect data is a measure of a condition which can be correlated to corrosivity. Instantaneous data is a measure of the corrosion rate or condition at a specific time, while historical data is a measure over a period of time. The weight loss of a coupon, for instance, provides a direct measure of the corrosion rate over a given length of time. On-line measurements of $\mathrm{pH}$, however, give an instantaneous indication of the corrosivity of the environment.

\section{CURRENT SRS CORROSION MONITORING TECHNIQUES}

The corrosion monitoring techniques that are commonly used at SRS are visual inspection, nondestructive examination, solution analyses, process monitoring, and coupon immersion.

\section{Visual Inspection}

Visual inspection is a fundamental step in assessing the condition of process equipment. The technique is simple and provides a comprehensive overview of corrosion damage, leakage, cracking, etc. The data are historical and indirect. The inspections may be recorded in several ways, such as in written records or photographic media. This technique can be time consuming, is often scheduled during downtime of equipment, and usually requires experienced personnel. Visual inspections, however, aid in determining locations for direct corrosion measurements. Waste Management Engineering at SRS has regularly inspected the waste tanks. An extensive library of photographs and video tapes is maintained of these inspections and provides an excellent corrosion history of the tanks.

\section{Nondestructive Examination}

Nondestructive examination methods (NDE) include ultrasonic inspection, eddy current testing and radiography. The three methods provide historical information on corrosion damage, but are limited by various constraints (i.e., wall thickness, access to surfaces, and material type). Automated ultrasonic inspection is the mosi viable method when only one side of a vessel or pipe is accessible. Radiography is preferred when both sides are accessible. Eddy current testing is invaluable for thin, non-ferromagnetic vessels or tubing. Each technique also has disadvantages; such as $x$-ray hazards for radiography and deterioration of probe reading for ultrasonic inspection. Similar to visual inspection, data are usually taken during downtime and require experienced personnel that are trained and certified for the specific NDE technique. SRS has certified NDE testing personnel for selection of the appropriate methods, test performance, and data analysis. The reactor areas have used these techniques extensively for inspection of welds, reactor vessel wall thicknesses, and integrity assessments of the heat exchangers.

\section{Solution Analysis}

The data from solution analyses are indirect measurements which indicate a corrosive condition. The data, therefore, provide supplementary information related to the corrosion process. Many species may be monitored depending upon the particular

Page 2 of 10 
process and include metal ions, dissolved solids, aggressive anions, inhibitors, and corrosion products. Concentrations of corrosion products can be correlated to a corrosion rate if the corroding area is known and if the corrosion products do not precipitate. Solution analyses are performed either in-line or by grab samples. For the SRS waste tanks, inhibitor level measurements are made at regularly scheduled times for each tank, while for the reactors concentrations of impurities such as chlorides and sulfates are regularly monitored.

\section{Process Monitoring}

Process parameters, like solution analyses, are also indicators of corrosive conditions. The range of process parameters which induce corrosion may be known or determined experimentally. Therefore, monitoring these parameters allows corrosive conditions to be avoided or changed when they occur. Typical process parameters that are monitored include temperature, pressure, $\mathrm{pH}$, solution conductivity, and fluid flow rates. Many of these parameters are commonly monitored in both the waste tanks and reactors at SRS.

\section{Coupon Immersion}

Coupon immersion is probably the most widely-used technique for direct measurement of an average corrosion rate and for assessment of localized corrosion. A coupon is exposed over a period of time so the collected data are historical. Coupons are exposed either under simulated conditions in the laboratory or in the actual process vessel. A realistic corrosion rate is obtained if the surface and metallurgical conditions of the coupons are similar to those of the process vessel. The actual conditions may be difficult to simulate, especially residual welding stresses which may exist in large structures. In general, set up of coupon immersion is easy and straightforward. A disadvantage of this technique, however, is that the measured corrosion rate cannot be correlated to upset process conditions. Standard methods for performing coupon tests are available from NACE and ASTM $(1,2)$. Coupon immersion has been used in the SRS reactors and waste tanks at various times and extensively in the laboratory for assessment and prediction of corrosion.

\section{ELECTRICAL RESISTANCE TECHNIQUE}

The electrical resistance (ER) technique is the single most common method for instantaneous corrosion measurements. ER was developed from the principle that the resistance of a metal is inversely proportional to the cross-sectional area. As a metallic object corrodes, the cross-sectional area decreases and the measured resistance increases. The resistance is monitored over time so that a corrosion rate is calculated from the difference of the initial and instantaneous thicknesses. A temperature compensation must be made since resistance is a function of the temperature. The resistance is measured with a probe which consists of a wire, sheet or tube section of the metal of interest. The advantages of this technique are that an instantaneous corrosion rate is obtainable, the rate can be correlated to process conditions, and measurements may be made continuously and remotely. The technique is applicable for both liquid and vapor environments.

The ER technique has several disadvantages as well. Localized corrosion cannot be distinguished from general corrosion. Variability in the measurements may occur 
either from electrical noise or fluctuations in temperature and fluid velocity. Erroneous measurements may also occur if a conductive film forms on the probe. Short-term measurements may be inaccurate, since the probe measures the resistance of the remaining metal and not the metal loss. ASTM has recently published a standard guide for on-line monitoring which discusses this technique (3).

\section{ELECTROCHEMICAL TECHNIQUES}

Electrochemical techniques are based on the theory of mixed potentials, where the corrosion process is composed of separate oxidation and reduction reactions. Oxidation, which generates electrons, occurs at an anode; and reduction, which uses the electrons, occurs at a cathode. The corrosion rate, which is measured as a current, depends on the kinetics of these reactions, as well as other factors, such as diffusion and the surface structure of the metal. Metals have corrosion potentials which vary with the relative anodic and cathodic areas on the surface, but where the rates of the oxidation and reduction reactions are equal.

The electrochemical techniques involve measuring the potential and current of a metal after an initial electrical perturbation or during undisturbed conditions. If a potential or current signal is applied to the metal, the changes in the corrosion potential and current are measured. Information about the corrosion process is obtained from this potential-current relationship. For the techniques that use only small potential signals, this relationship is assumed to be linear which is the SternGeary approximation (4). The electrochemical techniques of interest are potential measurements, linear polarization resistance, potentiodynamic polarization, zero resistance ammetry, impedance spectroscopy, and electrochemical noise measurements.

\section{Potential Measurements}

The measurement of the corrosion potential of a sample or process vessel during unperturbed conditions indicates whether the particular metal is passive (i.e., has a protective oxide) or is actively corroding. The corrosion potential varies for a metal depending on the specific environment. A direct determination of corrosion rate cannot be made from a potential measurement. The data can be correlated to process changes since potentials are measured instantaneously. Destruction or formation of an oxide, however, may take time after the onset of any specific condition.

Special instruments are necessary for making these measurements including a high impedance voltmeter and a reference electrode. The potential can be measured for a process vessel or a representative metallic sample. In either case, a probe must be inserted into the vessel which contains the reference electrode and may also have a metal sample and auxiliary electrode for current flow. The voltmeter and auxiliary equipment must be able to withstand the given environmental conditions surrounding a particular vessel and have dimensions that allow placement near these vessels. In general, modern equipment is durable, compact, and portable. Reference electrodes must also be durable. If contaminated by the process stream, the reference electrode would lead to faulty potential measurements. Frequent replacement of the reference electrode may be necessary. Data acquisition may be computerized or performed manually. The sensitivity and cost of all the instruments, however, are disadvantages for this and all electrochemical techniques.

Page 4 of 10 
Potential measurements were made with stainless steel and platinum electrodes in the corrosion loop of $\mathrm{K}$ reactor (5). The corrosion loop was a side stream of the process water system and was constructed of Type 304L stainless steel. Potential r.easurements were made to assess whether the process water piping was in a regime for stress corrosion cracking. This technique has also been used in the laboratory to assess the corrosion behavior of samples exposed to simulated process conditions for both the reactors and the waste tanks.

Actual potential measurements have also been made on various waste tanks $(6,7)$. Short-term corrosion probes were lowered into high-level waste tanks. Potential measurements were initially made on the tanks for investigating stress corrosion cracking (6). The tanks were found to have potentials in a regime for nitrate stress corrosion cracking. Appropriate corrective actions were taken to inhibit the tanks. Potential measurements were also made to verify that the nitrite inhibitor for the waste tank was effective for controlling pitting (7).

\section{Linear Polarization Resistance}

The linear polarization resistance technique (LPR) provides an instantaneous estimate of the general corrosion rate and can be monitored semi-continuously. This technique requires that a probe with a representative metallic sample be placed in the process stream. The probe must also contain a reference electrode for measuring potentials. A small potential or current ramp is applied to the sample, while the responding current or potential is monitored. A polarization resistance is determined from a linear potential-current relationship and is used to calculate a corrosion rate. The corrosion rate is inversely related to the polarization resistance. A typical potential ramp is approximately $40 \mathrm{mV}$ (i.e., $+/-20 \mathrm{mV}$ from the corrosion potential).

The most significant limitation for LPR is the accuracy of the measured corrosion rate. The rate is an approximate value because of the theoretical and practical assumptions made' in developing the technique. The degree to which these assumptions are met in an actual application governs the accuracy of the corrosion rate measurement. Each assumption has a different impact on the measurement which further complicates the accuracy. A weight loss measurement of the sample is an effective means to verify a corrosion rate determined from LPR. The technique has several other limitations. The process solution must be a conductive electrolyte. Consequently, this technique could be applied at SRS for the waste tanks, but would not be as useful for monitoring corrosion in the reactors. Information about localized corrosion is not obtained from this technique. Erroneous data can be taken if the reference electrode is contaminated or conductive deposits form on the sample. The placement of the probe in the process vessel is important for obtaining pertinent corrosion information. ASTM has recently published a standard guide for on-line monitoring which discusses this technique (3).

The instrumentation for polarization resistance is more complex than the other techniques. However, vendors supply compact, computerized units which facilitate the utilization of LPR. The equipment is available from either commercial vendors or DOE laboratories as discussed later. 


\section{Potentiodynamic Polarization}

Potentiodynamic polarization is a method more commonly used in the laboratory. The results of potentiodynamic polarization provide data on the oxidation and reduction reactions that occur in an environment. The procedure is similar to that for LPR except the data are obtained over a larger potential range, on the order of hundreds of millivolts $(\mathrm{mV})$. The ramped potentials and the resulting currents are plotted on polarization scans. The phenomena that are associated with corrosion rates are assessed with these scans. This technique, therefore, is analytical and is not used continuously. The scans are generally performed with a probe, but the process vessel may also be used.

There are several limitations with this technique. The polarization affects the sample by altering the surface. A fresh surface is usually required for each scan. The solution resistance is a problem if the process media is not sufficiently conductive and if the process equipment limits design of the probe. As for LPR, the necessary equipment is more complex than for other non-electrochemical techniques.

\section{Zero Resistance Ammetry}

Zero resistance ammetry (ZRA) provides information on specific types of corrosion depending on the metals used for the two electrodes in the probe. If the electrodes are of the same metal, an assessment of localized corrosion and the corrosion rate of the metal can be made. If the electrodes are made of dissimilar metals, an assessment of galvanic corrosion can be made. This electrode configuration has been traditionally called galvanic coupling. ZRA is performed by measuring the current that flows between the two electrodes. Initially, each electrode develops a unique corrosion potential which depends on the environment, the ratio of anodic to cathodic areas, and the electrode size. The electrodes shift to the same potential in a short period of time which induces a current to flow between the electrodes. The measured current is related to the corrosion rate ty Faraday's Law. The ZRA system is easy to install and provides simple measurements which are made continuously for both general and localized corrosion. The galvanic measurements are only approximate unless the probe is identical to the process vessel. As with many of the electrochemical techniques, erroneous measurements occur if the resistance of the process fluid is high. Poor results are also obtained if conductive or non conductive films deposit on the electrode surface which cause shorting or an increased resistance, respectively.

\section{Electrochemical Impedance Spectroscopy}

Electrochemical impedance spectroscopy (EIS) measurements are based on an electronic analysis of current and potential responses of a corrosion interface to an applied sinusoidal wave form. Wave forms at numerous frequencies are used to fully characterize the corrosion process. The analysis involves modeling the corrosion interface and reactions as a circuit of resistors and capacitors. The measurements provide data on the corrosion rate and processes, both general and local. The change in the measurements with time or process conditions provides the most useful information. EIS cannot be performed continuously because a time period is necessary for making the measurements which can range from several minutes to several hours. EIS has been used primarily in the laboratory, although systems are available for industrial applications. The installation of EIS is similar to most of the other electrical techniques. The same probes that are used for LPR or potentiodynamic polarization can be used for EIS, although sample design should be

Page 6 of 10 
optimized. A primary advantage of EIS is that reliable measurements can be made in low conductivity media unlike the other electrochemical techniques. EIS requires sophisticated instrumentation and extensive training for data interpretation.

\section{Electrochemical Noise Measurement}

Electrochemical noise measurement (ENM) is the monitoring of the fluctuations of the corrosion potential and current of an electrode. The fluctuations occur due to the corrosion at the electrode surface. Current and potential measurements are made between two electrodes of the same metal. Potential measurements may also be made relative to a stable reference electrode. The fluctuations or noise are of low amplitude and frequency, and depend on the type and rate of the corrosion process. The fluctuations have characteristic patterns or "signatures" for different corrosion processes. If a metal is passive, the fluctuations are small. As pits start to form, sharp exponential peaks occur in the fluctuations. The frequency of these peaks increases as the environment becomes more aggressive. The primary advantage of ENM is its sensitivity to localized corrosion. The measurements can be made continuously, but require a rigorous analysis to extract information pertinent to the corrosion rate. ENM also requires sophisticated instrumentation and development for specific applications, and is sensitive to electrical and hydrodynamic interferences.

\section{CORROSION MONITORING EQUIPMENT}

The corrosion monitoring equipment for industrial applications is provided by a number of companies. Rohrback Cosasco and Cortest Instrument Systems (formerly known as Petrolite) have the largest selection of all types of components for performing corrosion monitoring from coupon tests to the advanced electrochemical techniques. These two companies appear to dominate this area with Rohrback Cosasco being the pioneer. Their equipment is similar in features and capabilities. Approximately one year ago, West Valley Nuclear Services, another DOE site, installed a corrosion monitoring system of electrical resistance and polarization resistance probes that was produced by Rohrback Cosasco. The system is operational and the data are being analyzed.

Several companies, such as Gamry Instruments and Kontron Elektonik, also provide equipment and instrumentation primarily for the electrochemical techniques. Other companies, such as Metal Samples, Inc., provide only replacement corrosion probes that are compatible with the instrumentation provided by the other companies. Capcis Marche, Ltd., which is affiliated with the University of Manchester in England, also has an extensive selection of components. This company is on the leading edge of bring the advanced techniques of EIS and ENM to industry. Westinghouse Electric has a proprietary license with Capcis Marche to develop the ENM technique for the nuclear industry. ENM is being evaluated through a joint scoping study between SRS and the Westinghouse Science and Technology Center (WSTC) where the instrumentation is available. The sensitivity of the technique to inhibited and corrosive conditions is being investigated for waste tank applications.

At the Pacific Northwest Laboratories (PNL), a corrosion monitoring system was designed for waste tank applications. The available techniques are polarization resistance and potentiodynamic polarization. A probe had been used for three years in a waste tank at Hanford. The instrumentation is compact, easy to use, and reliable. 
Additional information about the PNL system can be found in Reference 8. PNL has been contracted to build a probe of similar design for SRS. This probe will be available during ITP startup.

\section{CONCLUSIONS}

Historically, SRS has extensively monitored its facilities for corrosion, especially in the reactor and waste tank areas. The data from the various techniques was primarily historical. Process control based on corrosion data was not available initially. However, several techniques are now available that allow on-line monitoring of corrosion. These techniques include electrical resistance, polarization resistance, and electrochemical noise measurements. This capability of on-line monitoring provides the opportunity for process control to avoid corrosive conditions.

The corrosion monitoring program for waste tanks associated with ITP and ESP could be improved with the addition of the newer techniques. A change in the processing conditions which increases corrosivity of the waste could be observed and addressed more quickly than with the older techniques. Therefore, the range of process conditions could also be increased, although experimental verification would be necessary before instituting such changes. A ER and LPR probe is being designed at PNL for trials in the SRS waste tanks. A joint study between WSTC and SRS is also being conducted to test the utility of ENM for waste tank applications.

\section{ACKNOWLEDGMENTS}

The author would like to thank the following people for their discussions during the preparation of this review: F. G. McNatt, E. W. Baumann, B. D. Howard, D. T. Hobbs, and G. R. Caskey, Jr. 


\section{REFERENCES}

1. NACE Standard Recommended Practice RP0775-87, "Preparation and Installation of Corrosion Coupons and Interpretation of Test Data in Oil Field Operations."

2. ASTM G4-84, "Standard Method for Conducting Corrosion Coupon Tests in Plant Equipment."

3. ASTM G96-90, "Standard Guide for On-Line Monitoring of Corrosion in Plant Equipment."

4. M. Stern and A. L. Geary, J. Electrochem. Soc., 104, 56 (1957).

5. E. W. Baumann and R. S. Ondrejcin, "Electrochemical Potentials of Stainless Steel anc Platinum in K-Reactor Moderator," DPST-88-621, July 6, 1988.

6. R. S. Ondrejcin, S. P. Rideout, and J. A. Donovan, Nuclear Technology, 44, 297 (1979).

7. D. F. Bickford, J. W. Congdon, and S. B. Oblath, Materials Performance, 27, 16 (1988).

8. Interoffice Memorandum, "Trip Report: Informational Meeting On The PNL Probe For Corrosion Monitoring", SRT-MTS-92-3022. 
WSRC-TR-92-472

UNCLASSIFIED

THIS PAGE INTENTIONALLY LEFT BLANK

Page 10 of 10 

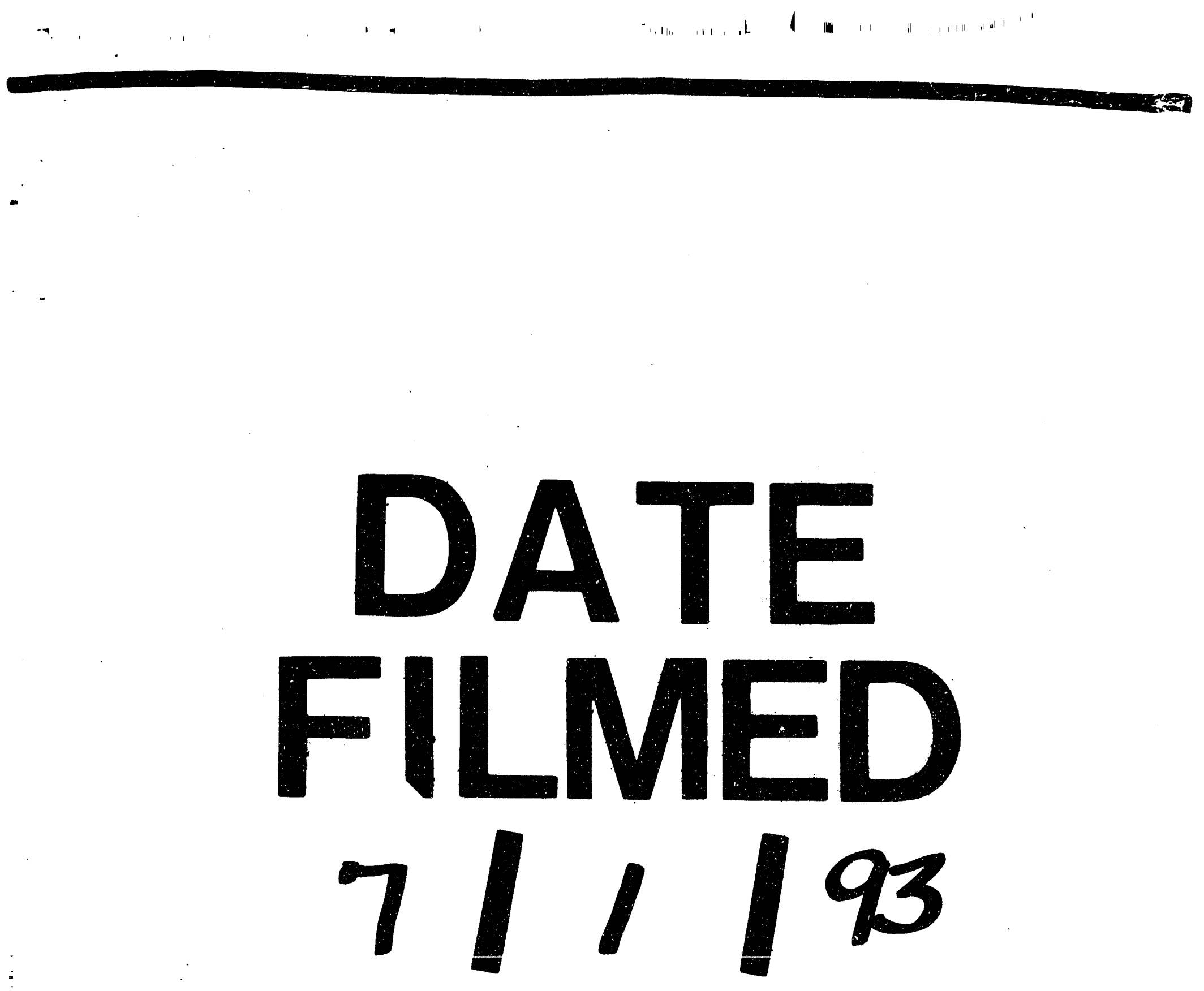

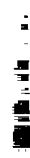


"1 P" 